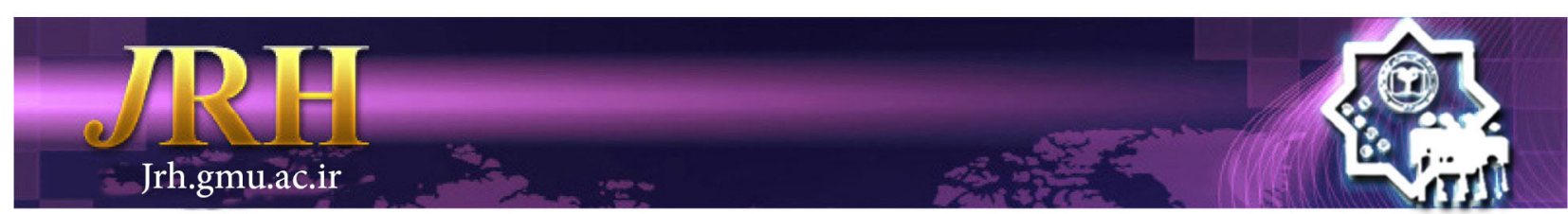

\title{
Prediction of marital adjustment based on attachment styles and deterministic thinking of couples among students
}

Mitra Takhttavani ${ }^{1}$, Karim Afsharinia ${ }^{1}$

\author{
Journal of Research \& Health \\ Social Development \& Health Promotion \\ Research Center \\ Vol. 8, No. 3, May \& Jun 2018 \\ Pages: 218- 225 \\ DOI: $10.29252 / j r h .8 .3 .218$ \\ Original Article
}

1. Department of Psychology, Faculty of Humanities Sciences, Sciences and Research of Kermanshah Branch, Islamic Azad University, Kermanshah, Iran

Correspondence to: Karim Afsharinia, Department of Psychology, Faculty of Humanities Sciences, Sciences and Research of Kermanshah Branch, Islamic Azad University, Kermanshah, Iran

Email: Irank.afsharineya@ iauksh.ir

Received: 22 Nov 2016

Accepted: 25 Oct 2017

How to cite this article: Takhttavani M, Afsharinia K. Prediction of marital adjustment based on attachment styles and deterministic thinking of couples among students. $J$ Research Health2018; 8(3): 218- 225.

\begin{abstract}
Choosing spouse and entering into marriage is a turning point in the growth and character development. Certainly, the choice of partner is one of the most important decisions in life. The aim of this study was to determine the predictive value of marital adjustment through study of variables of attachment and determinism as predictors of marital adjustment. The study used a correlation method and conducted on a sample of 50 student couples from Kermanshah Branch, Islamic Azad University that was selected by convenience sampling. To collect data, the marital adjustment scale, attachment scale for adults, and deterministic thinking scale were used. Except for variables of avoidant attachment and overall deterministic thinking, which were not correlated with marital adjustment, other variables (secure attachment, ambivalent attachment, determinism in interaction with others, philosophical determinism, determinism in future anticipation, and determinism in tragic events) had significant relationships with marital adjustment. All the variables were also able to predict marital adjustment. Based on significant correlation of the components of this research, the findings can be used to improve the compatibility of couples.
\end{abstract}

Keywords: Attachment, Couple, Marital, Student, Thinking

\section{Introduction}

Marriage is as one of the most important social practices to achieve emotional, psychological and security needs has everyone's approval. Marriage is the emotional and legal commitment that is assumed by persons in adulthood [1]. Choosing spouse and entering into marriage is a turning point in the growth and character development. Certainly, the choice of partner is one of the most important decisions in life [2].

Marriage not only satisfies the emotional, psychological, and sexual needs and security, but also provides an environment for growth of healthy and developed generations and a safe environment to satisfy the needs of its members. However, this concept is true if the relationship between spouses is generally healthy, warm, intimate, and free of stress and trouble [3].

Marital adjustment is a situation in which a couple often enjoys marital happiness and satisfaction. Satisfactory relations between the spouses can be evaluated based on mutual love, acceptance, understanding, and care [4]. Compatibility in marriage includes feelings of happiness, satisfaction, and mutual fulfillment 
of needs as it is considered for the foundation of many marriages [5].

Compatible couples are wives and husbands who have a lot of agreement with each other; they are satisfied with their relationships and its type and level; they enjoy their leisure time and properly manage their time and financial issues [6]. In general, it is accepted that marital adjustment is a multidimensional concept encompassing different factors that contribute to satisfaction or dissatisfaction in a relationship; therefore, there is no general consensus on the definition of marital adjustment. The reason for such disparity is originated from social, psychological, personality, and demographic factors that are associated with marital adjustment. Marital adjustment is a continuum and any change in the process of this continuum is possible [7].

Marital problems go back and forth in the continuum of marital adjustment as a response to the interactive elements of the human experience. Quality of marital relationship has a two-person property and it may not be transferred from one marriage to another [8]. One of the important factors drawing attention in recent years that has also an impact on marital satisfaction and adjustment is initial experience of individuals in relation to their parents or their emotional relationship with their parents in childhood. Some studies have tried to answer the question "how early experiences in childhood can affect his/her life in adulthood" [9]. Many psychologists and family therapists also consider couples' personality traits and children experiences as well as the quality of relationships among key members as the most important factor in the success or failure of their marriage [10].

One of the most influential theories is Bowlby's attachment styles that focuses on early relationships in the family environment as they can affect next relations of individuals. He states that intimate experience in childhood leads to the formation of schemas and named them as active cognitive models about intimate relationships [11]. Bowlby suggested that emotional boundaries with parents lead to the sense of security. On the other hand, negative relationships devoid of emotions and punishment in early childhood cause a person to experience an insecure attachment style. People with such attachment style often deem close relationships make them uncomfortable and thus, they endure a lot of pressure later in their marital relationship. Type of children's attachment affects the formation of romantic relationships in adulthood [12].

According to the model of adult attachment style, there are two levels of image of "self" (positive or negative) and two levels of image of "others" (positive or negative) along with two levels of anxiety and avoidance in people, which create one secure attachment style and three insecure attachment styles. The couple members who have these three insecure styles distrust their spouse and show low levels of solidarity and interdependence; they have difficulties in being committed and report lower levels of satisfaction with their relationships [13].

Cognitive distortions are among factors that play a role in processing of cognitive processes such as expectations, perceptions, and mental forms and patterns that each person expects from his/her spouse [14]. Deterministic thinking is one of the last known cognitive distortions, and it is the root of cognitive distortions that has an influence on conflict and marital satisfaction [15]. Many marital conflicts that lead to divorce ensue from couples' pertinacity, insistence on their point of view, and ignoring the other side, which may to a large extent be affected by high levels of deterministic thinking. Clinical studies during couple therapy show that reduced or corrected deterministic thinking in couples alongside other cognitive techniques result in marital satisfaction and consequently reduced rate of divorce [16].

Monga et al. [17] showed that Islamic married lifestyle has a significant effect on marital adjustment. In other words, the Islamic lifestyle had a significant positive correlation with marital adjustment. 
Shindel et al. [18] showed that avoidant and ambivalent attachment styles had a positive relationship with marital satisfaction and marital conflicts, a positive relationship with emotional intelligence and marital satisfaction, and a negative relationship with emotional intelligence and marital conflict.

Timm and Keiley [19] indicated that people who had a secure attachment had higher marital satisfaction than those who had avoidant and anxious attachment styles. Also, those with high differentiation had more marital satisfaction. There was no difference between men and women in terms of differentiation, but marital satisfaction was more in men than women.

Esere and Oladun [20] showed that relationship enhancement had an effect on increasing marital adjustment. Its dimensions include marital satisfaction, marital solidarity, couple agreement, and expression of love. As a result, skill of enrichment of relationship increases marital adjustment.

Safarzadeh, Esfahaniasl, and Bayat [21] showed that higher marital conflict had a direct relationship with depression and the more the marital conflict, the less the life satisfaction and self-esteem. Depression can be caused by lack of satisfaction on all dimensions of married life, such as job and it affects relationships with others.

Ramazanadeh, Noorbala and Abedi [22] showed that higher levels of marital conflict were associated with higher depression and lower life satisfaction and self-esteem.

Zia-ul-Haq et al. [23] showed that Emotionally Focused Couple Therapy had an impact on increasing marital compatibility. But its effects over time have not been confirmed.

Given the importance of balanced function of family life and preventing its collapse, understanding the factors associated with marital satisfaction and adjustment that strengthen family life seems necessary; thus, if factors affecting marital adjustment and satisfaction are considered, it can be expected that with increasing the levels of marital adjustment and satisfaction, many psychological, emotional, and social problems of family and the community reduce. Thus, this study aimed to investigate the prediction of marital adjustment based on attachment styles and deterministic thinking in student couples in 2015-2016 academic year.

\section{Method}

This research was an analytical and correlational study. In this study, the statistical population comprised couples aged 20-40 years selected from Kermanshah (the west of Iran) branch of Islamic Azad University in 2015-2016 academic year. In order to collect data and test the study hypothesis, of all 20-40-year-old couples in the study setting, 50 couples were selected by convenience sampling and three questionnaires (Marital Adjustment, Adult Attachment Scale, and deterministic thinking scale) were administered to them.

In this research tools included:

The Dyadic Adjustment Scale (DAS): The DAS is a 32-item measure in a variety of response formatsdeveloped to measuredyadic adjustment. Spanier [24] defined dyadic adjustment as "... a process, the outcome of which is determined by the degree of: 1) troublesome dyadic differences; 2) interpersonal tensions and personal anxiety; 3) dyadic satisfaction; 4) dyadic cohesion; and 5) consensus on matters of importance to dyadic functioning". Spanier's [24] development of the instrument was based on a review of over 15 preexisting measures of marital satisfaction and adjustment. Spanier [24] also identified four subscales: dyadic consensus, dyadic satisfaction, dyadic cohesion, and affective expression. Spanier [24] argued that the subscales could be used alone "without losing confidence in the reliability and validity of the measure". Due to its inception, the DAS has sparked a vast amount of research examining the validity and factor structure of the instrument. Total DAS scores have been consistently shown to discriminate between distressed and no distressed couples and have been shown to identify couples with a high likelihood of divorce.

The Adult Attachment Scale (AAS): The scale consists of 18 items scored on a 5-point Likert- 
type scale. It measures adult attachment styles named "Secure", "Anxious", and "Avoidant", defined as: secure $=$ high scores on close and depend subscales, low score on anxiety subscale, anxious $=$ high score on anxiety subscale, moderate scores on close and depend subscales, avoidant $=$ low scores on close, depend, and anxiety subscales. Collins and read [25] reported Cronbach's alpha coefficients of 0.69 for close, 0.75 for depend, and 0.72 for anxiety subscales. Test-retest correlations for a 2-month period were 0.68 for close, 0.71 for depend, and 0.52 for anxiety subscales.

Deterministic Thinking Questionnaire (DTQ):

This was developed with the intention of measuring deterministic thinking based on the theories in relation with cognitive theories, Islamic viewpoints [26] and clinical experiences [27]. This scale has 36 questions, which are scored on a 4-point Likert scale ranging from $1=$ "completely agree" to 4="completely disagree". Thus, the increase in the score of an individual means the increase in the rate of deterministic thinking. For validating the questionnaire in two introductory and conclusive stages of the main project, exploratory, confirmative, and convergent factorial analyses have been used. The results of analyzing the main constituents show that the questionnaire consists of 5 factors which explain 38 percent of the variance on the whole. These are General determinism, determinism in interaction with others, Philosophical determinism, determinism in future anticipation, and determinism in tragic events. The results of the confirmative factorial analysis approved the accuracy of collected data. The validity convergence of the deterministic thinking questionnaire is detected based on its correlation coefficient with the score of Beck's depression questionnaire. This amount obtained from the research sample by the calculation of the Pearson correlation coefficient in a group of 100 participants was equal to $r=\% 33$ that is statistically significant at a level lower than 0.01 . The validity of the whole scale was equal to $(0.821)$ via internal consistency coefficient and it was equal to 0.78 by reassessing (for a week).

Descriptive statistics including frequency, percentage, mean, and standard deviation and inferential statistics including correlation tests (Pearson and regression) were used to analyze data. . After collecting the questionnaires, coding, and data entry, SPSS-19 software was used to analyze the data in significant level 95\%. The researcher received from each participant a conscious / verbal satisfaction about the measurement of the study variables. For participants explained the advantages and disadvantages of participating in the study, the researcher's expectations of the samples, how to select the sample. The participants were assured that their personal information will remain confidential and not released. If any obstacle to the confidentiality of information occurred, the participants would be notified by the researcher in advance. The researcher was responsible for the privacy of participants and adoption of appropriate measures to prevent its spread. If any obstacle occurred to the confidentiality of information, the participants would be notified by the researcher in advance.

\section{Results}

In this study, the age of participants ranged between 20 and 44 years with the mean (standard deviation) of 24.1 (3.22). In terms of education, $70(70 \%)$ were Bachelor's degree (BA) students, 26 (26\%) Master's degree (MA) students, and $4 \mathrm{PhD}$ students (4\%). Economic level of 5 students (5\%) was low, 70 students $(70 \%)$ were in the middle level, and 25 students (25\%) had high economic status.

Table 1 Pearson correlation coefficients between attachment styles and marital adjustment

\begin{tabular}{ccccc}
\hline \multirow{2}{*}{ Variables } & \multicolumn{3}{c}{ Marital adjustment } \\
\cline { 2 - 5 } & Secure & Sig. & r value & Size \\
\hline \multirow{2}{*}{$\begin{array}{c}\text { Attachment } \\
\text { styles }\end{array}$} & Avoidant & 0.264 & $0.323^{* *}$ & 100 \\
& Anxious & 0.008 & -0.113 & 100 \\
& & & &
\end{tabular}


As Table 1 shows, there was a significant positive correlation between secure attachment style and marital adjustment, which means that couples who have secure attachment style have more marital adjustment. Also, anxious attachment style and marital adjustment showed a significant negative correlation, which means that couples who have anxious/ ambivalent attachment style experience less marital adjustment. Furthermore, there was no correlation between marital adjustment and avoidant attachment style.

Table 2 Pearson correlation coefficients between the components of deterministic thinking and marital adjustment

\begin{tabular}{clccc}
\hline \multirow{2}{*}{ Variables } & \multicolumn{3}{c}{ Marital adjustment } \\
\cline { 3 - 5 } & General determinism & Sig. & r value & Size \\
\hline \multirow{3}{*}{$\begin{array}{c}\text { Deterministic } \\
\text { thinking }\end{array}$} & Determinism in interaction with others & 0.22 & 0.005 & 100 \\
& Philosophical determinism & $-0.199^{* *}$ & 100 \\
& Determinism in future anticipation & 0.01 & $-0.233^{* *}$ & 100 \\
& Determinism in tragic events & 0.001 & $-0.286^{* *}$ & 100 \\
& & $-0.019^{* *}$ & 100 \\
\hline
\end{tabular}

The results of correlation analysis in Table 2 show that deterministic thinking in the interaction with others (-0.199), philosophical deterministic thinking $(-0.233)$, Determinism in future anticipation $(-0.286)$, and Determinism in tragic events $(-0.019)$ had a significant negative correlation with marital adjustment. This means that with enhancement of deterministic thinking, marital adjustment decreases. General deterministic thinking showed no correlation with marital adjustment.

Table 3 Variance analysis of regression related to attachment styles and marital adjustment

\begin{tabular}{lcccccccc}
\hline $\begin{array}{l}\text { Source of } \\
\text { variance }\end{array}$ & Sum of Squares & df & Mean Square & F & Sig. & R & $\mathrm{R}^{2}$ & SE \\
\hline Regression & 1207.218 & 1 & 1207.218 & 5.476 & 0.02 & -0.34 & 0.11 & 6.81 \\
Residual & 21605 & 98 & 220.462 & & & & & \\
Total & 22812.510 & 99 & & & & & & \\
\hline
\end{tabular}

Based on the results of Table 3 , the observed F-value (5.476) is significant at $\mathrm{p} \geq 0.05$ and

$11 \%$ of the variance of marital adjustment is explained by attachment styles $\left(\mathrm{R}^{2}=0.11\right)$.

Table 4 Variance analysis of deterministic thinking and marital adjustment

\begin{tabular}{llccccccc}
\hline Source of variance & Sum of Squares & df & Mean Square & F & Sig. & R & R $^{2}$ & SE \\
\hline Regression & 261.875 & 1 & 261.875 & 1.138 & 0.04 & -0.29 & 0.09 & 6.77 \\
Residual & 22550.635 & 98 & 230.109 & & & & & \\
Total & 22812.510 & 99 & & & & & & \\
\hline
\end{tabular}

According to Table 4, the observed $\mathrm{F}$ value (1.138) is significant at $\mathrm{p} \geq 0.05$ and $9 \%$ of the variance of marital adjustment is explained by deterministic thinking $\left(\mathrm{R}^{2}=0.09\right)$.

Table 5 Regression coefficients of marital adjustment with respect to attachment styles and deterministic thinking

\begin{tabular}{lcccc}
\hline Variables & $\mathrm{B}$ & $\beta$ & $\mathrm{t}$ statistic & Sig. \\
\hline Constant & 120.785 & & 7.053 & 0.000 \\
Attachment Styles & 1.729 & -0.242 & -2.462 & 0.01 \\
Deterministic thinking & 1.198 & 0.230 & 1.319 & 0.02 \\
\hline
\end{tabular}

As Table 5 shows, attachment styles and deterministic thinking can significantly predict marital adjustment $(p<0.05)$. Also, given that the coefficient between the predictor variable and deterministic thinking is positive, so less deterministic persons have higher marital adjustment. Also, considering the coefficient between the predictor variable and attachment styles, people with secure attachment style have more marital adjustment.

\section{Discussion}

The results showed a positive significant relationship between secure attachment style and marital adjustment, which means that couples that have secure attachment style 
experience more marital adjustment. This is consistent with the findings of Greil [28], Lopez, Riggs, Pollard, Hook [29], Porter, Keefe Davis, Rumble, Scipio, Garst [30], Perry, Ettinger, Mendelson, Le [31], and Mondor, McDuff, Lussier, Wright [32].

It can be said in the explanation of this finding that the attachment style is a fundamental and effective structure in interpersonal relationships. Attachment-based strategies include procedural and declarative knowledge about oneself, others and adjustment of emotions. The declarative knowledge includes optimistic beliefs about control of distress and trust in the good intentions of others and a sense of personal competence to deal with threats $[33,34]$. These beliefs are the core elements of secure attachment, resulting in a positive interaction of the individual and attachment images. During such interactions, the individual learns that distress can be controlled and external barriers can be eliminated [35]. $\mathrm{S} /$ he also realizes that others can have good intentions in their relationships. Gaining knowledge that falls within security strategies of attachment has rules. When the person is in difficult situations, one seeks help and support of others seeking in order to eliminate distress by such support and peace. Relatively secure people have learned that their behavior can reduce distress and break down barriers and getting help from others when threatened is an effective strategy to reduce distress [36].

The relationship problems are manifestations of failure in having sense of security in the relationship, or failure in the satisfaction of attachment needs. Turmoil in relations between spouses occurs a result of failure of the relationship in which one or both of the couples are looking for a safe anchor [37]. The lack of a secure anchor for a spouse may significantly degrade the marital adjustment and satisfaction.

Anxious people are likely to have activated attachment system frequently for prolonged periods of time. This would lead to a sense of being threatened, even in the face of events that are not considered a threat by other adults naturally [38].
According to cognitive views, mental health and illness depend on the manner of perception and interpretation of the world and surrounding environment. According to such view, the quality of experience of the reality is determined by perception. The closer the perception of the surrounding environment and its reflection in the mind to the reality, the more logical and mentally healthier the relation of the individual with the environment and the way s/he reacts to the events [39].

The human's relationships with the world are not always direct and away from the influence of subjective factors; but the mental structures and the laws governing the perception interfere with the process of relation of mind with outside world that lead to common consequences in the social dimension such as misunderstanding in interpersonal relationships [40].

According to the cognitive model, content of perceptions and inferences of any person form as a result of relatively stable underlying cognitive schemas or structures like individual structures. Schema contains fundamental beliefs about human nature and their relationships, which are relatively stable and may even become inflexible. Many schemas related to relationships and interactions of couples are learned in early years of life and from primary sources such as primary family, customs of life, the media, and the early emotional experiences and other relationships. According to attachment theorists, communication patterns of "self" with others are schemas that are affected by automatic thoughts and emotional responses in the face of important people in life [41]. In addition to the schema that brings to a relationship with them, each of couple members creates schemas that are specific to such relationship.

Marital conflict occurs when the spouses are not able to satisfy the attachment needs of each other. The turbulent marital relations, in fact, represent a failure of the couple in communication with secure attachment models. The spouses create emotional 
responses such as fear, anxiety, and despair rather than satisfying each other's attachment needs. Failure causes the initial emotional responses to become secondary emotional responses such as anger, hostility, revenge, and guilt which in turn, reduce level of marital adjustment [42].

\section{Conclusion}

In fact, people with insecure attachment styles (avoidant and anxious) face trouble in their intimate relationships in very early stages and inject negative emotions in their relationships. Thus, given the critical role of attachment styles in intimate relationships like marriage, it is expected that martial adjustment and marital satisfaction be predicted based on attachment styles. Today, most couples' problems are caused by such cognitive distortions. Identifying such cognitive distortions by couples or even therapist can be a step towards resolving such distortions.

\section{Acknowledgements}

Authors would like to thank the participants who kindly collaborated in this project.

\section{Contribution}

"The authors declared that they have no competing interests."

\section{Conflicts of Interest}

"The authors declare that they have no competing interests."

\section{Funding}

The author(s) received no financial support for research, authorship, and/or publication of this manuscript.

\section{References}

1- Smith TW, Baron CE, Grove JL. Personality, emotional adjustment, and cardiovascular risk: Marriage as a mechanism. J Pers2014, 82(6): 502-14.

2- Dryden C. Being married, doing gender: a critical analysis of gender relationships in marriage. London: London Routledge; 1999. pp: 25-40.

3- Lamela D, Figueiredo B, Bastos A, Feinberg M. Typologies of post-divorce coparenting and parental wellbeing, parenting quality and children's psychological adjustment. Child Psychiatry Hum Dev2016; 47(5): 716-28.

4- Zerach G, Greene T, Solomon Z. Secondary traumatization and self-rated health among wives of former prisoners of war: The moderating role of marital adjustment. J Health Psychol2015; 20(2): 222-35.

5- Camisasca E, Miragoli S, Di Blasio P. Is the relationship between marital adjustment and parenting stress mediated or moderated by parenting alliance? EJOP2014; 10(2): 235-54.

6- Teti DM, Crosby B, McDaniel BT, Shimizu M, Whitesell CJX. Marital and emotional adjustment in mothers and infant sleep arrangements during the first six months. Monogr Soc Res Child Dev2015; 80(1): 160-76.

7- Arshad M, Mohsin MN, Mahmood K. Marital adjustment and life satisfaction among early and late marriages. JEP2014; 5(17): 83-90.

8- Carr D, Freedman VA, Cornman JC, Schwarz N. Happy marriage, happy life? Marital quality and subjective well-being in later life. J Marriage Fam2014; 76(5): 930-48.

9- Bögels SM, Hellemans J, Van Deursen S, Römer M, Van der Meulen R. Mindful parenting in mental health care: effects on parental and child psychopathology, parental stress, parenting, coparenting, and marital functioning. Mindfulness 2014; 5(5): 536-51.

10- Galovan AM, Holmes EK, Schramm DG, Lee TR. Father involvement, father-child relationship quality, and Satisfaction with family work actor and partner influences on marital quality. J Fam Issues2014; 35(13): 1846-67.

11- Chung MS. Pathways between attachment and marital satisfaction: The mediating roles of rumination, empathy, and forgiveness. Pers Individ Dif2014; 30(70): 246-51.

12- Taycan SE, Kuruoglu AC. The evaluation of the relationships between marital adjustment, attachment styles, temperament and character features. Turk Psikiyatri Derg2014; 25(1): 9-18.

13-Lowell A, Renk K, Adgate AH. The role of attachment in the relationship between child maltreatment and later emotional and behavioral functioning. Child Abuse Negl2014; 38(9): 1436-49.

14- Chung MC, Jalal S, Khan NU. Posttraumatic stress disorder and psychiatric comorbidity following the 2010 flood in Pakistan: Exposure characteristics, cognitive distortions, and emotional suppression. Psychiatry2014; 77(3): 289-304.

15- Jensen TM, Willoughby BJ, Holman TB, Busby DM, Shafer K. Associations between family and interpersonal processes and emerging adult marital paradigms: does adult attachment mediate? J Adult Dev2015; 22(1): 50-62.

16- Navidian A, Bahari F. The impact of mixed, hope and forgiveness focused marital counselling on interpersonal cognitive distortions of couples filing for divorce. $J$ Psychiatr Ment Health Nurs2014; 21(7):658-66. 
17- Monga M, Alexandrescu B, Katz SE, Stein M, Ganiats T. Impact of infertility on quality of life, marital adjustment, and sexual function. Urology2004; 63(1): 126-30.

18- Shindel AW, Nelson CJ, Naughton CK, Ohebshalom M, Mulhall JP. Sexual function and quality of life in the male partner of infertile couples: prevalence and correlates of dysfunction. J Urol2008; 179(3): 1056-9.

19- Timm TM, Keiley MK. The effects of differentiation of self, adult attachment, and sexual communication on sexual and marital satisfaction: A path analysis. $J$ Sex Marital Ther2011; 37(3): 206-23.

20- Esere MO, Oladun C. Obstacles and suggested solutions to effective communication in marriage as expressed by married adults in Kogi State, Nigeria. Procedia Soc Behav Sci2014; 114: 584-92.

21- Safarzadeh S, Esfahaniasl M, Bayat MR. The relationship between forgiveness, perfectionism and intimacy and marital satisfaction in Ahwaz Islamic Azad University married students. Middle-East Journal of Scientific Research2011; 9(6): 778-84.

22- Ramazanadeh F, Noorbala AA, Abedi-Nia N. Emotional adjustment in infertile patients. JournalFaculty of Nursing and Midwifery martyr Beheshti University of Medical Sciences and Health Services 2010; 20(70): 36- 44.

23- Zia-ul-Haq MS, Hassan Abadi H, Hashemabadi Ghanbari BA, Modares Gharavi M. Excited couple therapy based on marital adjustment. J Fam Stud2012; 8(29): 44.

24- Kurdek LA. Dimensionality of the dyadic adjustment scale: evidence from heterosexual and homosexual couples. J Fam Psychol1992; 6(1): 22.

25- Collins NL, Read SJ. Adult attachment, working models, and relationship quality in dating couples. J Pers Soc Psychol1990; 58(4): 644-63.

26- Younesi J, Bahrami F. Prediction of rate of marital satisfaction among Tehranian couples by deterministic thinking. Journal of Iranian Psychologists2009; 14: 56-68. 27- Younesi J. The major role of cognitive Misconceptions" Equality in thinking" in psychological disorders. Journal of social sciences and humanities The Research institute of seminary \& University (Hawzeh va Ddneshgah)2004; 10: 8-29.

28- Greil AL, Slauson K, McQuillan J. The experience of infertility: a review of recent literature. Sociol Health Illn2010; 32(1): 140-62.

29- Lopez JL, Riggs SA, Pollard SE, Hook JN. Religious commitment, adult attachment, and marital adjustment in newly married couples. J Fam Psychol2011; 25(2): 301-9. 30- Porter LS, Keefe FJ, Davis D, Rumble M, Scipio C,
Garst J. Attachment styles in patients with lung cancer and their spouses: associations with patient and spouse adjustment. Support Care Cancer2012; 20(10): 245966.

31- Perry DF, Ettinger AK, Mendelson T, Le HN. Prenatal depression predicts postpartum maternal attachment in low-income Latina mothers with infants. Infant Behav Dev2011; 34(2): 339-50.

32- Mondor J, McDuff P, Lussier Y, Wright J. Couples in therapy: Actor-partner analyses of the relationships between adult romantic attachment and marital satisfaction. The Am J Fam Ther2011; 39(2): 112-23.

33- Beck LA, Pietromonaco PR, DeBuse CJ, Powers SI, Sayer AG. Spouses' attachment pairings predict neuroendocrine, behavioral, and psychological responses to marital conflict. J Pers Soc Psychol2013; 105(3): 388-424.

34- Moreira H, Crespo C, Paredes T, Silva S, Canavarro MC, Dattilio FM. Marital relationship, body image and psychological quality of life among breast cancer patients: the moderating role of the disease's phases. Contemp Fam Ther2011; 33(2): 161-78.

35- Miga EM, Gdula JA, Allen JP. Fighting fair: Adaptive marital conflict strategies as predictors of future adolescent peer and romantic relationship quality. Soc Dev2012; 21(3): 446-60.

36- Mirecki RM, Chou JL, Elliott M, Schneider CM. What factors influence marital satisfaction? Differences between first and second marriages. $J$ Divorce Remarriage2013; 54(1): 78-93.

37- Theiss JA, Estlein R, Weber KM. A longitudinal assessment of relationship characteristics that predict new parents' relationship satisfaction. Pers Relatsh2013; 20(2): 216-35.

38- Wade JB, Hart RP, Wade JH, Bajaj JS, Price DD. The relationship between marital status and psychological resilience in chronic pain. Pain Res Treat2013; 2013: 928473.

39- Nagy ME, Theiss JA. Applying the relational turbulence model to the empty-nest transition: Sources of relationship change, relational uncertainty, and interference from partners. J Fam Commun2013; 13(4): 280-300.

40- Allendorf K. Schemas of marital change: from arranged marriages to eloping for love. J Marriage Fam2013; 75(2): 453-69.

41- Fraley RC, Heffernan ME, Vicary AM, Brumbaugh $\mathrm{CC}$. The experiences in close relationships relationship structures questionnaire: a method for assessing attachment orientations across relationships. Psychol Assessment2011; 23(3): 615-25.

\footnotetext{
Copyright(C) 2016 ASP Ins. This open-access article is published under the terms of the Creative Commons Attribution-NonCommercial 4.0 International License which permits Share (copy and redistribute the material in any medium or format) and Adapt (remix, transform, and build upon the material) under the Attribution-NonCommercial terms.
} 